\title{
Rapid Determination of Tellurium in Organic Compounds by Microwave Plasma-Atomic Emission Spectrometry
}

\author{
ANASTASIA V. LASTOVKA ${ }^{1,2}$, VALENTINA P. FADEEVA ${ }^{1,2}$, \\ MAKSIM A. BAZHENOV ${ }^{1 *}$ and VERA D.TIKHOVA ${ }^{1}$ \\ ${ }^{1}$ N. N. Vorozhtsov Novosibirsk Institute of Organic Chemistry of Siberian Branch of Russian Academy \\ of Sciences (NIOCH SB RAS), 9 Lavrentiev Ave., Novosibirsk, 630090, Russia. \\ ${ }^{2}$ Novosibirsk National Research State University, 1 Pirogova Str., Novosibirsk, 630090, Russia. \\ *Corresponding author E-mail: maxbajenoff@gmail.com \\ http://dx.doi.org/10.13005/ojc/330612
}

(Received: August 04, 2017; Accepted: September 15, 2017)

\begin{abstract}
A method for quantitative tellurium measurement in tellurium-containing organic compounds (TOC) by a microwave plasma-atomic emission spectrometer Agilent 4100 has been suggested. One of ways to decompose the sample - the oxygen flask combustion or the acid decomposition in a heating block, can be applied. It has been demonstrated with telluradiazole derivatives and some other TOC with 20 to $58 \%$ tellurium content that the method proposed is suitable for precise and easy determination of tellurium. Elements such as nitrogen, sulfur, potassium, selenium present in the TOC do not interfere in the procedure. The relative error of the analysis is $1-5 \%$.
\end{abstract}

Keywords: Tellurium-containing organic compounds, Sample decomposition, Microwave Plasma-Atomic emission Spectrometry, Agilent 4100.

\section{INTRODUCTION}

Chemistry of tellurium organic compounds (TOC) has intensively been developing in recent decades. The increased interest in this field is due to widely use of these substances as catalysts in organic reactions (e. g. rubber vulcanization), inhibitors of metal corrosion, insecticides, fungicides, components of special photographic materials, pharmaceuticals, etc. ${ }^{1-5}$.

In view of great practical importance of these compounds for science and technology, a large number of analytical methods for the determination of tellurium in various objects were developed: gravimetric methods based on the precipitation of elemental tellurium by treating with inorganic and organic reducing agents ${ }^{6-8}$; titrimetric methods based on redox reactions using iodideanion, salts of iron(II), chromium(III) or titanium(III) as reducing agents, as well as potassium permanganate or dichromate as oxidizing agents for Te(IV) $)^{9-11}$; electrochemical methods, which allow one to determine the tellurium and selenium at simultaneous presence with a sensitivity being $10^{-5}$ $\mathrm{M}^{12,13}$; spectrophotometric methods based on the 
formation of complexes with sulfur-containing organic reagents (diethyldithiocarbamate, thiurea and their derivatives, bismuthiol II, and so on $)^{14,15}$ or on the formation of ion pairs of tellurium acido complexes with organic bases-pyrazolone derivatives and rhodamine dyes ${ }^{16,17}$.

Three spectrophotometric methods were used to determine small tellurium content in the environment (water, plant material, soil), and thin telluride films ${ }^{18}$. These methods are based on the formation of three differently colored Te-complexes. Magenta color was obtained by oxidation of 4-bromophenyl-hydrazine by tellurium in a basic medium followed by condensation of the product with $\mathrm{N}$-(1-naphthyl) ethylenediamine dihydrochloride. Red color was obtained by oxidation of 3-methyl2-benzothiazolinone hydrazone hydrochloride followed by condensation with the chromotropic acid. Orange color was obtained by oxidation of 2,3 dimethoxy strichnidin-10-one in an acid medium. Beer's law was obeyed in the range of $1.0-25 \mathrm{mg} / \mathrm{mL}$ for magenta product, $0.7-20 \mathrm{mg} /$ $\mathrm{mL}$ for red, and $0.3-15 \mathrm{mg} / \mathrm{ml}$ for orange. The authors noted that these methods were simpler and more sensitive than the other known ones, and standard deviations were $0.2-0.3 \%$.

Several dyes were proposed for the extraction-photometric determination of tellurium: Victoria blue 4R, Brilliant green, Rhodamine 4C. The latter dye was used, for example, in the analyses of tellurium salt solutions and semiconductor films ${ }^{19}$. The extraction-photometric redox process was described for the selective determination of selenium(IV) and tellurium(IV) with the detection limit of $5 \cdot 10^{-5} \mathrm{mg} / \mathrm{L}$, based on different oxidability of analytes by antimony $(\mathrm{V})$ ion associates in acidic or alkaline media ${ }^{20}$. The method does not require either preconcentrating and separating analytes, or masking the associated components in analyte mixtures.

The possibility of using benzal green as a reagent for the rapid determination of tellurium(IV) is shown by Amelin et al., ${ }^{21}$ The dye was immobilized on viscose fabrics and it formed ion associate with molibdotellurous heteropolyacid with different color intensity. The range of detectable concentrations is $0.01-0.1 \mathrm{mg} / \mathrm{L}$ of $\mathrm{Te}(\mathrm{IV})$.
Currently, spectrometric methods are most commonly used for the tellurium determination. Atomic absorption spectrometry was used in the analysis of geological samples (ores, minerals, rocks) with tellurium content $0.01-100 \mathrm{mg} / \mathrm{g}^{22}$, $\mathrm{coal}^{23}$, in lead and lead alloys ${ }^{24}$, in the environment (water, plants, biological materials) ${ }^{25-27}$. Such techniques as atomic emission spectrometry (AES) with inductively coupled (ICP) or microwave (MP) plasma, in conjunction with mass spectrometry ${ }^{28-}$ ${ }^{31}$, atomic fluorescence spectrometry ${ }^{32-34}$, the optical emission spectrometry ${ }^{35}$ are used for the tellurium and tellurium trace analysis in various objects. In most of these works, tellurium is converted to the hydride before the spectrometric measurements to increase the sensitivity of the method. The atomic emission method with continuous hydride generation was used for the simultaneous determination of $\mathrm{Sb}, \mathrm{As}, \mathrm{Bi}, \mathrm{Ge}$, Se, and $\mathrm{Te}$ in a set of sediment samples ${ }^{36}$. The detection limit for $\mathrm{Te}$ was $6.5 \mu \mathrm{g} / \mathrm{L}$.

The tellurium determination was made in the gold concentrate by ICP-AES ${ }^{37}$. It was shown that tellurium may be separated from the majority of interfering components (such as $\mathrm{Ag}, \mathrm{Pb}, \mathrm{Zn}, \mathrm{Si}$, $\mathrm{Ca}, \mathrm{Mg}, \mathrm{Al}, \mathrm{Fe}$ ) in the sample by coprecipitation with arsenic to eliminate the matrix effect. The detection limit of Te was $4.23 \mu \mathrm{g} / \mathrm{g}$.

Doronina et al., ${ }^{38}$ investigated the possibility of group preconcentration of $\mathrm{As}, \mathrm{Cd}$, Se, and $\mathrm{Te}$ for the subsequent simultaneous determination of these elements by ICP-AES in the technogenic raw materials. Sorption of arsenic, selenium, tellurium, and cadmium oxyanions on iron, lanthanum, and magnesium hydroxides was used. The relative standard deviation of the method was $9-2.5 \%$ under the content of determined elements from $10^{-4}$ to $10^{-1} \%$ mass. It was found that the presence of iron (> $500 \mu \mathrm{g} / \mathrm{mL}$ ) can lead to $10 \%$ decrease of the Te $(214.2 \mathrm{~nm})$ signal.

When new organotellurium compounds are synthesized they should be completely described. It requires quantitative determination of so-called basic biogenic elements (carbon, hydrogen, nitrogen) as well as tellurium. Unlike small tellurium content in the above-mentioned inorganic, biological and ecological objects of 
analysis, tellurium content in synthetic TOC may be up to tens of percent. The first necessary step in TOC analysis is a complete decomposition of organic matter. In the few published studies on the analysis of TOC, they used wet decomposition in mineral acids ${ }^{39-41}$, burning in a stream of oxygen at $900--950^{\circ} \mathrm{C}$ or the oxygen flask combustion ${ }^{42,43}$. Afterwards, tellurium was determined by the methods of gravimetry ${ }^{42}$, potentiometry ${ }^{40}$, spectrophotometry ${ }^{41,43}$. The main disadvantages of all these methods are their long duration and tediousness. MP-AES method for the determination of tellurium in TOC has not previously been used, although it is characterized by high accuracy and selectivity, rapidity, efficiency, wide range of detectable concentrations, and it does not involve converting tellurium into a single analytical form.

The goals of this work are finding the conditions for sample preparation (decomposition) and developing a procedure for quantitative determination of tellurium in synthetic multielement tellurium-containing organic compounds by MP-AES using the Agilent 4100 spectrometer.

\section{EXPERIMENTAL}

\section{Instruments}

Analysis was performed with Agilent 4100 MP-AES (Australia) microwave plasma-atomic emission spectrometer. The sample supply system was a self-adjusted one-piece quartz torch. Plasma was generated by igniting with auxiliary argon and maintained with nitrogen. The configuration of the plasma was vertically-oriented with axial observation and computer-control of the plasma viewing position. A Curny-Terner monochromator, self-adjusted, with a $600 \mathrm{~mm}$ focal length was used. Holographic gitter with 2400 lines $/ \mathrm{mm}$ was used. The spectral range was $178-780 \mathrm{~nm}$ and spectral resolution was $0.050 \mathrm{~nm}$. A High-speed CCD detector, having $532 \times 128$ pixels, with a quantum efficiency of $>90 \%$ was used; it was cooled to $0{ }^{\circ} \mathrm{C}$ with a Peltier element. A double-pass glass cyclonic spray chamber and a One-Neb micronebulizer were used.

HotBlock $^{\mathrm{TM}}$ Digestion System (25-Well $100 \mathrm{~mL}$ ) Agilent 4107 (Australia) was applied for acid decomposition of organic samples. The samples and reagents were weighed with Mettler Toledo AT20 (Switzerland) microanalytical balance and Sartorius CP224S (Germany) analytical balance.

\section{Reagents and materials}

Solutions of $\mathrm{H}_{2} \mathrm{O}_{2}, \mathrm{KNO}_{3}, \mathrm{HCl}, \mathrm{HNO}_{3}$ (Reakhim, Russia) were prepared from reagentgrade and high-purity chemicals. Oxygen gas from a cylinder with a purity of $99.7 \%$ was used for burning. The specimen holder was made of platinum wire $(\varnothing=0.6-1.0 \mathrm{~mm})$ with a purity of $99.99 \%$. Blue ribbon ash-free filters were cut into $3 \times 3 \mathrm{~cm}$ squares with $1 \mathrm{~cm}$ branches, impregnated with a saturated $\mathrm{KNO}_{3}$ solution and dried; an $\mathrm{H}$-type polyethylene film; glycerol, polyurethane foam, twice-distilled water.

\section{Reference material}

Certified reference material of tellurium(IV) ions-Interstate Certified Reference Material 0529:2003 (GSO 6082-91) (Russia).

\section{RESULTS AND DISCUSSION}

In proceeding of maintained goals, our work was performed as follows: choosing an analytical wavelength, finding suitable reference material of Te for constructing calibration curve, condition selection for decomposition of samples, making measurements. Below we briefly describe general observations.

\section{Analytical wavelength selection}

Comparative measurements of the Te standard solutions were made at three wavelengths: 214.281; 225.902; $238.578 \mathrm{~nm}$. The calibration curves were made followed by measurement of the Te solution (5 ppm) (Table.1).

It is clear from Table 1 that only two emission lines are appropriate for the measurements. Atomic line $214.281 \mathrm{~nm}$ was selected due to its maximal intensity, but the measurement at this wavelength should be carried out after the full nitrogen purge of monochromator. Although this emission line is influenced by vanadium, tantalum, and cadmium, however, such elements are not encountered in the studied synthetic organic compounds. 
Table. 1: The results of determining $5 \mathrm{ppm}$ Tellurium at three emission lines $(P=0.95 ; n=7)$

\begin{tabular}{lccc}
\hline$\lambda, \mathrm{nm}$ & 214.281 & 225.902 & 238.578 \\
$\mathrm{I}$, rel. & 4885.9 & 1147.2 & 2127.8 \\
the equation of the & $565.81 c_{i}-3.46$ & $\left(80.98 c_{i}\right) /\left(1-0.04 c_{i}\right)$ & $201.37 c_{i}-4.81$ \\
calibration curve & & & rational \\
approximation & linear & 1.00000 & linear \\
$r$ (correlation coefficient) & 1.00000 & $4.33 \pm 0.11$ & 0.99999 \\
Found Te, ppm & $5.04 \pm 0.02$ & & $5.08 \pm 0.04$ \\
\hline
\end{tabular}

\section{The study of sample decomposition}

A tellurium-containing organic compound, 3,4dicyano-1,2,5-telluradiazole $\left(\mathrm{C}_{4} \mathrm{~N}_{4} \mathrm{Te}\right)$, was used to study the methods of sample preparation. Composition and structure of this substance are confirmed by elemental analysis, NMR, IR and MS spectrometry. The purity of the compound is $99.9 \%$.

When using the oxygen flask combustion, we tested three different solutions for absorbing the combustion products: 1) $10 \mathrm{~mL}$ of $0.1 \mathrm{M} \mathrm{HCl}$; 2) $3 \mathrm{~mL}$ of $\mathrm{HNO}_{3}$ (conc.) $+5 \mathrm{~mL} \mathrm{H} \mathrm{O}+2 \mathrm{~mL} \mathrm{H}_{2} \mathrm{O}_{2}$; 3) 10 $\mathrm{mL}$ of $\mathrm{HNO}_{3}$ (conc.). The best results were obtained with absorbing mixtures 1) and 3).

When using the decomposition mixture with nitric acid and perhydrol (8 $\mathrm{mL} \mathrm{HNO}_{3}$ (conc.) + $2 \mathrm{~mL}$ of $30 \% \mathrm{H}_{2} \mathrm{O}_{2}$ ) to resolve samples in the heating block, we experimentally selected the temperature of the reaction (from 60 to $130^{\circ} \mathrm{C}$ ) and the duration (45 to $60 \mathrm{~min}$.) of the process. Finally, satisfactory results were obtained after decomposition of the sample for one hour at $130^{\circ} \mathrm{C}$.

The following results were obtained in the discussed conditions $(P=0.95 ; n=6)$ : with the oxygen flask combustion- $55.5 \pm 1.7 \%$; with the acid decomposition in the heating block-55.5 $\pm 0.3 \%$. The calculated tellurium content in 3,4-dicyano$1,2,5$-tellurodiazole is $55.1 \%$. Therefore, both methods can be used to decompose the TOC when analyzing tellurium.

\section{Procedures for the decomposition of TOC}

The oxygen flask combustion. A portion of $0.1 \mathrm{M} \mathrm{HCl}(10 \mathrm{~mL})$ was placed into a $500-\mathrm{mL}$ Erlenmeyer's flask which was filled with oxygen from a cylinder. A weighed quantity of a telluriumcontaining compound $(\sim 2.0-3.0 \mathrm{mg})$ wrapped into a small square of a potassium nitrate-impregnated ash-free filter with a piece of polyethylene film was fixed on a Pt wire; the branch of the filter was ignited, placed into the flask, and burned. After the combustion having been completed, the flask was thoroughly shaken for $5 \mathrm{~min}$. and placed into a fridge for $40 \mathrm{~min}$. to complete the absorption of combustion products.

The acid decomposition in a heating block. A weighed quantity of a tellurium-containing compound $(\sim 2.0-3.0 \mathrm{mg})$ was placed into polypropylene $100 \mathrm{~mL}$ vessel. $\mathrm{HNO}_{3}(8 \mathrm{~mL})$ and $30 \% \mathrm{H}_{2} \mathrm{O}_{2}(2 \mathrm{~mL})$ were added to the probe. The vessel was covered with a lid (not tightly) and placed in a heating block HotBlock ${ }^{\mathrm{TM}}$ Digestion System, Agilent 4107 . It took $60 \mathrm{~min}$. at $130^{\circ} \mathrm{C}$ to complete decomposition of the substance.

After the decomposition, the inside of the flask or vessel was quantitatively transferred into a $100-\mathrm{mL}$ volumetric flask rinsing its walls, stopper, wire or lid with twice-distilled water, and diluted to the mark. The tellurium content in the resulting solution was determined by MP AES using a preliminarily constructed calibration curve.

\section{Construction of calibration curves}

The calibration curve was made using the solutions obtained with dilution of certified reference material of tellurium(IV) ions (GSO 6082-91). We used 4 concentrations of $\mathrm{Te}(\mathrm{IV}): 1,5,10,15 \mathrm{ppm}$. The intensity of Te emission line at $214.241 \mathrm{~nm}$ was recorded on the spectrometer. The data were processed with the Agilent MP Expert software (version 1.4.0.4317). The conditions of measurements on the spectrometer were as follows: pressure in the spray chamber was $100 \mathrm{kPa}$, uptake delay$15 \mathrm{~s}$, read time $-3 \mathrm{~s}$, stabilization time - $15 \mathrm{~s}$, pump speed-15 ppm, number of replicates- 3 , automatic background correction. A linear intensity 
dependence of the recorded signal ( $r \geq 0.99998)$ was observed for reference substance solutions in this concentration range.
Various tellurium-containing organic compounds have been analyzed according to the developed technique (Table 2).

Table. 2: Results of tellurium determination in TOC using two methods of sample preparation $(P=0.95, n=5)$

Substance

1-Thiophenyl-3,4-dicyano-

$$
\mathrm{C}_{22} \mathrm{H}_{29} \mathrm{KN}_{4} \mathrm{O}_{6} \mathrm{STe}
$$

19.81

$19.81 \pm 0.3$

$19.92 \pm 0.3$

1,2,5-tellurodiazole 18 crown6 potassium salt complex

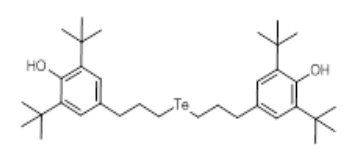

4,4'-(Tellurobis(propane-3,1 diyl)) bis(2,6-di-tert-buthylphenol)

$$
\mathrm{C}_{34} \mathrm{H}_{54} \mathrm{O}_{2} \mathrm{Te}
$$

$20.72 \pm 0.6$

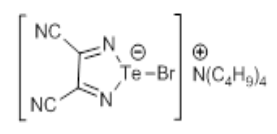

Tetrabuthylammonium 1bromo3,4-dicyano-1,2,5-telluradiazolide

$$
\mathrm{C}_{20} \mathrm{H}_{36} \mathrm{~N}_{5} \mathrm{BrTe}
$$

$23.3 \pm 1.0$

$23,6 \pm 1,7$<smiles>CCN(CC)C(=O)CSC(=S)N(CC)CC</smiles>

bis-(Diethylamino-thioxomethanesulfenyl)-tellane

$$
\mathrm{C}_{10} \mathrm{H}_{20} \mathrm{~N}_{2} \mathrm{~S}_{4} \mathrm{Te}
$$

30.08

$30.22 \pm 0.13$

$29.9 \pm 0.3$<smiles></smiles>

Potassium 1isoselenocyanato-<smiles>N#Cc1n[se]nc1C#N</smiles>

3,4-dicyano-1,2,5-telluradiazolide<smiles>Nc1ccccc1CNc1ccccc1N</smiles>

2,2'-Ditellanediyldianiline

$$
\mathrm{C}_{5} \mathrm{~N}_{5} \mathrm{KSeTe}
$$

$$
\mathrm{C}_{4} \mathrm{~N}_{4} \mathrm{Te}
$$

$\mathrm{C}_{12} \mathrm{H}_{12} \mathrm{~N}_{2} \mathrm{Te}_{2}$
58.07

$57.99 \pm 0.18$

$57.89 \pm 0.05$

* The determination could not be completed due to insufficient quantity of the sample. 


\section{CONCLUSION}

We have proposed the rapid, accurate and cost-effective technique for the tellurium determination in synthetic multielement organic compounds. It involves the oxygen flask combustion or acid decomposition followed by measuring Te content by the MP-AES method. Elements such as nitrogen, sulfur, potassium, selenium included in the TOC do not influence the quantitative determination of tellurium. Statistical processing was performed on the results obtained by the decomposition of 5-6 weighed portions for each of substances analyzed. The relative error is in the range of $1-5 \%$.

\section{ACKNOWLEDGEMENTS}

We are grateful to Prof. Andrey V. Zibarev and employees of the Laboratory of Heterocyclic Compounds (NIOCH SB RAS) for the samples provided for our study.

\section{REFERENCES}

1. Comasseto, J.; Barrientos-Astigarraga, R. Aldrichimica Acta. 2000, 33, 66-102.

2. Petragrani, N.; Stefani, H. A. Tetrahedron. 2005, 61, 1613-1679.

3. Petragrani, N; Stefani, H. A. Tellurium in Organic Synthesis, 2nd ed.; Academic Press: London, 2007.

4. Princival, J.; Dos Santos, A.; Comasseto, J. J. Braz. Chem. Soc. 2010, 21, 2042-2054.

5. Wei, Cao; Lu, Wang; Huaping, Xu. Nano Today. 2015, 10, 717-736.

6. Wang, J.; Cheng, K. Microchem J. 1970, 15, 607-621.

7. Asuero, A. Microchem J. 1979, 24, 217-233.

8. Singh, N.; Rastogi, K.; Agrawal, R. J. Indian Chem. Soc. 1985, 62, 394-396.

9. Johnson, R.; Frederickson, D. Anal. Chem. 1952, 24, 866-867.

10. Geiersberger, K.; Durst, A. Z. Analyt. Chem. 1952, 135, 11-14.

11. Lenher, V.; Wakefield, H. J. Am. Chem. Soc. 1923, 45, 1423-1425.

12. Ivanova, Z.; Ignatenko, Å.; Tarasova, V. J. Anal. Chem. 1973, 28, 1980-1984.

13. Locatelli, C. Anal. Bioanal. Chem. 2005, 381, 1073-1081.

14. Terpinski, E. Analyst. 1988, 113, 1473-1475.

15. Yoshida, H.; Taga, M. Talanta. 1966, 13, 185-191.

16. Nazarenko, I.; Ermakov, A. Analiticheskaya Chimiya Selena i Tellura (Analytical Chemistry of Selenium and Tellurium). Nauka: Moscow, 1971 (in Russian).

17. Balogh, I.; Andruch, V. Analyt. Chim. Acta. 1999, 386, 161-167.
18. Suvardhan, K.; Krishna, P.; Puttaiah, E.; Chiranjeevi, P. J. Analyt. Chem. 2007, 62, 1032-1039.

19. Kish, P.; Balog, I.; Andrukh, V.; Goloib, M. Zh. Anal. Khim. 1990, 45, 915-919 (in Russian).

20. Sergeev, G.; Shlyapunova, E. Analitika $i$ Kontrol. 2006, 10, 195-199 (in Russian).

21. Amelin, V.; Koroleva, O. J. Anal. Chem. 2009, 64, 1275-1278.

22. Torgov, V.; Vall, G.; Demidova, M.; Yatsenko, V. Chemical Geology. 1995, 124, 101-107.

23. Oda, S.; Arikawa, Y. Bunseki Kagaku. 2005, 54, 1033-1037.

24. Mesko, M.; Pozebon, D.; Flores, E.; Dressler, V. Analyt. Chim. Acta. 2004, 517, 195-200.

25. Najafi, N.; Tavakoli, H.; Alizadeh, R.; Seidi, S. Analyt. Chim. Acta. 2010, 670, 18-23.

26. Kaplan, M.; Cerutti, S.; Salonin, J.; Gasguez, J.; Martinez, L. J. of AOAC International. 2005, 88, 1242-1246.

27. Grotti, M.; Abelmoschi, M.; Soggia, F.; Frache, R. Anal. Bioanal. Chem. 2003, 375, 242-247.

28. Yu, C.; Cai, Q.; Guo, Z.; Yang, Z.; Khoo, S. Anal. Bioanal. Chem. 2003, 376, 236-242.

29. de Quadros, D.; Borges, D. Microchem J. 2014, 116, 244-248.

30. Yang, G.; Zheng, J.; Tagami, K.; Uchida, S. Talanta. 2013, 116, 181-187.

31. Yu, S.; Zhang, H.; Jin, Q. Gaodeng Xuexiao Huaxue Xuebao. 1999, 11, 84-86.

32. Cava-Montesinos, P.; Cervera, M.; Pastor, A.; de la Guardia, M. Analyt. Chim. Acta. 2003, 481, 291-300.

33. Wang, F.; Zhang, G. Appl. Spectr. 2011, 65, 315-319. 
34. Chen, Y.; Alzahrani, A.; Deng, T.; Belzile, N. Analyt. Chim. Acta. 2016, 905, 42-50.

35. Kaplan, M.; Cerutti, S.; Moyano, S.; Olsina, R.; Martinez, L.; Gasquez, I. Instrumentation Sciences\&Technology. 2004, 32, 423-431.

36. Morrow, A.; Wiltshire, G.; Hursthouse, A. Atomic Spectroscopy. 1997, 18, 23-28.

37. Zhang, H.; Ni, W.; Xiao, F.; Mao, X.; Yao, M.; Cui, R. Yejin Fenxi / Metallurgical Analysis. 2016, 36, 32-36.

38. Doronina, M.; Shiryaeva, O.; Filatova, D.; Baranovskaya, V.; Karpov, Yu. Zavodskaya
Laboratoriya. Diagnostika Materialov. 2013, 79, 3-7 (in Russian).

39. Kruse, F.; Sanftner, R.; Suttle, J. Anal. Chem. 1953, 25, 500-502.

40. Masson, M. Microchim. Acta. 1976, 65, 399411.

41. Thavornyutikarn, P. J. Organomet. Chem. 1973, 51, 237-239.

42. Anisimova, G.; Klimova, V. J. Anal. Chem. 1980, 35, 607-609.

43. Clark, E.; Al-Turaihi, M. J. Organomet. Chem. 1976, 118, 55-58. 